\title{
The bright and dark sides of motivation as predictors of enjoyment, intention, and exercise persistence
}

\author{
Filipe Rodrigues $^{1,2,3}$ (D) | Diogo Santos Teixeira ${ }^{4}$ | Henrique Pereira Neiva ${ }^{1,2}$ (D) |
}

12 Luís Cid ${ }^{2,3}$ | Diogo Monteiro, 2,3

${ }^{1}$ Department of Sports Science, Beira Interior University, Covilhã, Portugal

${ }^{2}$ Research Center in Sport Sciences, Health Sciences and Human Development (CIDESD), Vila Real, Portugal

${ }^{3}$ Sport Science School of Rio Maior (ESDRM-IPSantarém), Rio Maior, Portugal

${ }^{4}$ Lusófona University, Lisbon, Portugal

\section{Correspondence}

Filipe Rodrigues, Beira Interior University, Rua Marquês de Ávila e Bolama, 6201-001 Covilhã.

Email: ptfiliperodrigues@gmail.com

\section{Funding information}

Portuguese Foundation for Science and Technology, I.P, Grant/Award Number: UID/DTP/04045/2019

\begin{abstract}
Objective: The present study aimed to examine the bright and dark sides of motivation, based on self-determination theory, as predictors of enjoyment, intention to continue exercising, and exercise persistence. In addition, we analyzed the mediation role of each variable and tested the model invariance between male and female
\end{abstract} 3 exercisers.

Methods: A total of 575 gym exercisers (female $=230$ ) aged between 18 and 65 years $(M=34.07$; $S D=11.47)$ participated in this study. All participants had at least 6 months of regular exercise practice; exercise frequency of the participants ranged from 2 to 7 sessions per week $(M=3.52 ; \mathrm{SD}=1.28)$ and training sessions lasted approximately 30 and 120 minutes $(\mathrm{M}=61.54$; $\mathrm{SD}=17.64)$. Participants completed a multisection questionnaire assessing interpersonal behaviors, basic psychological needs satisfaction and frustration, behavioral regulations, enjoyment, and intentions to continue exercising. Exercise persistence was assessed 6 months after initial assessment using gym computer system attendance records. Several analyses, namely, confirmatory factor analysis, structural equation modeling, serial mediation analysis, and structural invariance testing, were performed to increase theoretical and empirical knowledge.

Results: Positive associations were observed among the bright side of motivation, enjoyment, intention to continue exercising, and persistence. On the other hand, the dark side of motivation was negatively associated with the bright side constructs, enjoyment, intention, and exercise persistence. Both measurement $\left[\chi^{2}(370)=1496.708, \chi^{2}\right.$ / $\mathrm{df}=4.05 ; \mathrm{B}-\mathrm{S} P<.001, \mathrm{CFI}=0.907, \mathrm{TLI}=0.901, \mathrm{SRMR}=0.056, \mathrm{RMSEA}=0.073$ $(\mathrm{CI} 90 \%=0.063,0.083)]$ and structural models $\left[\chi^{2}(393)=2484.994, \chi^{2} / \mathrm{df}=6.323\right.$; B-S $P<.001, \mathrm{CFI}=0.908, \mathrm{TLI}=0.900, \mathrm{SRMR}=0.075, \mathrm{RMSEA}=0.071(\mathrm{CI}$ $90 \%=0.067,0.075)]$ displayed acceptable fit to the data. The results also showed that basic psychological needs satisfaction, autonomous motivation, enjoyment, and intention to continue exercising were significant mediators. However, enjoyment had the highest effect on exercise persistence. In addition, structural model invariance was confirmed between male and female exercisers.

Conclusion: Motivational determinants have implications for predicting emotional, cognitive, and behavior-related outcomes. Individuals should perceive exercise 
instructors as supportive and exercising as a fun activity to endorse long-term exercise persistence.

\section{K E Y W O R D S}

behavioral regulation, enjoyment, exercise persistence, intentions, interpersonal behaviors, psychological mediators

\section{$1 \mid$ INTRODUCTION}

Exercise participation is of the upmost importance, as it represents a healthy way to reduce chronic diseases and mortality. However, according to the last Eurobarometer survey, ${ }^{1}$ over $65 \%$ of the European population is physically inactive, and individuals report lack of time and motivation as the main reasons for being sedentary. In fact, motivation seems to be the most important variable explaining exercise participation. In recent years, self-determination theory (SDT) $)^{2}$ has been used as the "go to framework" for defining the impact of motivational determinants on emotional, cognitive, and behavioral outcomes in an exercise context. ${ }^{3}$ In this regard, Vallerand ${ }^{4}$ proposed the Hierarchical Model of Intrinsic and Extrinsic Motivation (HMIEM) to explain how different levels of generalityglobal (environment), contextual (domains in life), and situational (personal state)_are responsible for an individual's behavior. According to the HMIEM sequence, social factors (eg, perceived interpersonal behaviors from exercise instructors) affect different types of motivation, depending on how basic psychological needs (BPN: autonomy, competence, and relatedness) are met. Contingent on the quality of behavior motivation (autonomous and controlled motivation), behavior motivation can lead to different emotional, ${ }^{5}$ cognitive, ${ }^{6}$ or self-reported behavioral outcomes. $^{7}$

Nevertheless, few studies have tested the full sequence of the HMIEM by considering the bright and dark sides of the SDT tenets. ${ }^{8}$ In addition, several studies ${ }^{9,10}$ suggest that the theoretical sequence can be extended, whereby an emotional outcome (ie, enjoyment) could predict a cognitive outcome (ie, intention to perform the behavior in the future). Since intention to continue exercising is the most proximal determinant of behavior enactment, ${ }^{11}$ it is possible to speculate that higher levels of enjoyment would predict higher levels of intention, resulting in higher rates of behavior commitment (eg, exercise persistence). Thus, to test this hypothetical model is of the upmost importance, since, to the best of our knowledge, no study has ever considered "expanding" the HMIEM by considering both sides of motivation and objectively measuring behavioral persistence in the exercise context.

\subsection{Theoretical framework}

The first part of the HMIEM explains how the environment (eg, social factors) influences psychological mediators. In other words, perceived interpersonal behaviors from others (in this study, exercise instructors' behaviors) will determine the satisfaction or frustration of BPN. In terms of exercise, several studies ${ }^{7,12,13}$ have shown that perceived supportive behaviors (eg, perception of positive feedback and emotional connection from the exercise instructor) are positively associated with BPN satisfaction. On the other hand, thwarting behaviors (eg, perception of negative feedback and social exclusion) have been associated with BPN frustration. ${ }^{14}$ Ryan and Deci $^{2}$ propose that perceived supportive and thwarting behaviors would have a significant association with BPN satisfaction and frustration, respectively.

The next part of the causal sequence explains how the satisfaction and/or frustration impacts behavioral regulation toward exercising. Teixeira and Silva ${ }^{15}$ have revealed in exercise settings that BPN satisfaction is positive and significantly related to autonomous motivation (ie, individuals partake in the behavior because they value the activity), whereas negative and significantly associated with controlled motivation (ie, the person engages in the behavior to obtain external rewards or to avoid negative consequences such as guilt). Conversely, BPN frustration has an negative relationship with autonomous and a positive with controlled motivation, as demonstrated theoretically ${ }^{3}$ and empirically. ${ }^{15}$

The last part of the HMIEM explains how motivational regulations are associated with cognitive, emotional, and behavioral consequences. In the context under analysis, previous results show that autonomous motivation has a positive, although controlled motivation a negative, relationship with enjoyment. ${ }^{16}$ In addition, higher levels of autonomous motivation have been shown to represent higher degrees of intention toward exercising in the future. ${ }^{6,17}$ Other studies have demonstrated that autonomous motivation was positively associated with exercise persistence ${ }^{7}$ and adherence, ${ }^{18}$ whereas controlled motivation had an inverse effect.

Recently, Monteiro and Pelletier ${ }^{9}$ tested the impact of enjoyment (ie, emotional outcome) on intention to continue practicing sports (ie, cognitive outcome) in 799 swimmers. The results showed a positive and significant association 
between these factors, explaining the mediating role of enjoyment between autonomous motivation and intention. In this regard, higher levels of intention to continue behavior performance seem crucial, since Ajzen ${ }^{11}$ has stated it theoretically as the most proximal determinant. Higher levels encourage exercise participation; thus, acting without intent is more likely to promote dropout. ${ }^{19,20}$ Therefore, autonomous motivation may not necessarily be a single determinant of exercise participation, since enjoyment and intention to continue can likewise influence its performance on the long term.

\section{2 | Present research}

To the best of our knowledge, few studies have tested the HMIEM sequence in exercise, ${ }^{16}$ or in similar domains. ${ }^{9,10}$ However, studies considering the bright (perceived supportive behaviors, BPN satisfaction, and autonomous motivation) and dark (perceived thwarting behaviors, BPN frustration, and controlled motivation) sides of motivation are scarce, ${ }^{8}$ and, in an exercise context, these studies are almost nonexistent. In addition, studies expanding the HMIEM, considering the prediction of one outcome to another (eg, enjoyment $\rightarrow$ intention), are uncommon, ${ }^{9}$ and to the best of our knowledge, no study has measured and added observable outcomes, such as behavior persistence on the model sequence. This gap in the literature regarding the effect of enjoyment on behavioral intentions and behavioral performance has been previously reported ${ }^{21}$ and highlighted by systematic reviews, ${ }^{22,23}$ showing the particular importance of enjoyment and intentions on behavior enactment.

In the present study, in addition to the hypothetical model based on HMEIM, two mediation models will be carried out: one model testing the dark side and the other model considering the bright side of motivation constructs. Invariance analysis will also be performed to examine the adequacy of the structural model between male and female exercisers.

\section{$2 \mid$ METHODS}

\subsection{Participants and procedures}

Examining sample characteristics, 575 Portuguese gym exercisers (female $=230$ ) aged between 18 and 65 years $(\mathrm{M}=34.07 ; \mathrm{SD}=11.47)$ participated in this study. All participants had at least 6 months of regular exercise practice, the self-reported exercise frequency ranged from 2 to 7 sessions per week $(\mathrm{M}=3.52 ; \mathrm{SD}=1.28)$, and each training session lasted between 30 and 120 minutes $(\mathrm{M}=61.54$; $\mathrm{SD}=17.64)$.
Ethical approval (registration reference: CE-UBI-pJ2018-044:ID683) was obtained prior to data collection. Subsequently, the study's objectives and data collection procedures were explained to several gym managers. After approval, gym members were contacted at the reception desk during different periods of the day and were asked to participate voluntarily in this study. We specifically asked for permission to collect data regarding the frequency of the use of their gym, reinforcing anonymity and confidentiality. Informed consent was obtained before delivering the questionnaires and membership number to observe if exercise persistence had been attained.

Data regarding motivational determinants, enjoyment, and intention were collected, and participants' exercise persistence was assessed 6 months after initial assessment using gym attendance system computer records. Gym exercisers received no compensation for their participation. The time required for the completion of the questionnaires was approximately 15 minutes.

\section{$2.2 \quad$ Measures}

\subsubsection{Perceived interpersonal behaviors}

The Interpersonal Behavior Questionnaire (IBQ) Portuguese version in exercise,${ }^{24}$ assessing supportive and thwarting behaviors, was used. The 24-item scale (four items per factor) measures autonomy (item 1: "My exercise instructor supports my choices"), competence (item 9: "My exercise instructor encourages me to improve my skills"), and relatedness (item 5: "My exercise instructor really likes to spend time with me") support, as well as autonomy (item 8: "My exercise instructor imposes his opinions"), competence (item 22: "My exercise instructor questions my ability to overcome challenges"), and relatedness (item 24: "My exercise instructor does not build empathy with me") thwarting, regarding exercisers' perception of fitness instructors' behaviors during gym activities. Participants were asked to respond to the IBQ based on their perceptions of need-supportive and needthwarting behaviors taking into account the instructor they have had the most often contact with during their weekly training sessions. Participants responded using a Likerttype scale ranging from 1-“do not agree" to 7-"totally agree" for each item, and two composite factors were created as follows: perceived supportive and thwarting interpersonal behaviors. The confirmatory factor analysis (CFA) of the IBQ in the present study displayed the following fit: $\left[\chi^{2}(237)=473.030, \chi^{2} / \mathrm{df}=1.799\right.$; B-S $P<.001$, CFI $=0.950$, TLI $=0.930$, SRMR $=0.041$, RMSEA $=0.045($ CI 90\% $=0.036,0.053)]$. 


\subsection{2 | Basic need satisfaction and frustration}

The Basic Psychological Need Satisfaction and Frustration Scale Portuguese version in exercise (BPNSFS-E) ${ }^{25}$ was used to assess autonomy (item 1: "When I exercise I feel a sense of choice and freedom in the exercises I undertake"), competence (item 5: "When I exercise I feel confident that I can do exercises well"), and relatedness (item 9: "When I exercise I feel connected with others in the gym") satisfaction, as well as autonomy (item 8: "When I exercise I feel forced to do training sessions I would not choose to do"), competence (item 12: "When I exercise I feel disappointed with my performance"), and relatedness (item 1: "When I exercise I feel that the relationships I have at the gym are just superficial") frustration. Participants responded to items using a 5-point scale ranging from 1-“totally disagree" to 5- "totally agree", and two composite factors were created, one composite factor for BPN satisfaction and one composite factor for BPN frustration. Similar procedures have been used in the past, ${ }^{15}$ and those previous procedures support the use of this scale in Portuguese exercisers. The CFA of the BPNSFS in the present study displayed the following fit: $\left[\chi^{2}(237)=831.845, \chi^{2} / \mathrm{df}=2.78\right.$; B-S $P<.001$, $\mathrm{CFI}=0.961, \mathrm{TLI}=0.949, \mathrm{SRMR}=0.071, \mathrm{RMSEA}=0.064$ $(\mathrm{CI} 90 \%=0.0759,0.069)]$.

\subsection{3 | Behavioral regulations}

The Behavioral Regulation Exercise Questionnaire (BREQ3) Portuguese version ${ }^{26}$ was used, measuring all six behavioral regulations according to the SDT motivational continuum. This 18-item version scale measures amotivation (item 1: "I do not see why I have to exercise"), external (item 14: "I exercise because others will be dissatisfied with me if I do not"), introjected (item 3: "I exercise because I feel guilty when I fail a training session"), identified (item 16: "I exercise because I value the benefits of exercising"), integrated (item 5: "I exercise because it is related to my life goals"), and intrinsic (item 12: "I exercise because I like my training sessions") motivation. Participants answered items using a 5-point scale anchored from 0- "totally disagree" to 4- "totally agree" on how they perceive their motivation when exercising, and two composite factors were created, one composite factor for autonomous (intrinsic motivation, integrated, and identified regulation) and another composite factor for controlled motivation (introjected and external regulation, and amotivation), reducing the number of parameters to be estimated and to avoid collinearity issues. It is worth noting that although some authors suggest that amotivation stands for "the lack of motivation to act on a certain behavior" 27 and should therefore not be considered as controlled motivation, we use this term because of several scientific advances. Jowett and Adie $^{28}$ have shown that amotivation is located on the same continuum as the other behavior regulations, next to external regulation without discontinuity. These authors also explain that the mere occurrence of the behavior indicates that at least some motivation is present, even if the individual feels confused or helpless with respect to behavior participation. Past studies support the use of this scale for measuring behavioral regulations in Portuguese exercisers. ${ }^{15,26}$ The measurement model of BREQ-3 in the present study displayed the following fit: $\left[\chi^{2}(120)=384.421, \chi^{2} / \mathrm{df}=3.20 ; \mathrm{B}-\mathrm{S} P<.001\right.$, $\mathrm{CFI}=0.938, \mathrm{TLI}=0.921, \mathrm{SRMR}=0.057, \mathrm{RMSEA}=0.062$ $($ CI $90 \%=0.055,0.069)]$.

\subsection{4 | Enjoyment}

The Physical Activity Enjoyment Scale (PACES) Portuguese version ${ }^{29}$ was used. This 8-item (eg, "It is very stimulating") scale assesses the level of agreement on enjoyment when exercising using a 7-point scale ranging from 1- "totally disagree" to 7-"totally agree." Recent studies support the use of this scale in Portuguese exercisers. ${ }^{29}$ The measurement model of PACES in the present study displayed the following fit: $\left[\chi^{2}(21)=304.006, \chi^{2} / \mathrm{df}=14.48\right.$; B-S $P<.001$, $\mathrm{CFI}=0.933$, TLI $=0.911, \mathrm{SRMR}=0.049, \mathrm{RMSEA}=0.054$ $($ CI 90\% $=0.044,0.64)]$.

\subsection{5 | Intention to continue exercising}

We followed Ajzen ${ }^{30}$ recommendations and created three items to evaluate intention to continue exercising after 6 months: "I will continue to exercise in the next 6 months as I currently do or in a very similar way (same type, frequency, duration and intensity)," "I plan to continue practicing physical exercise in the next six months as I do today or in a very similar way (same type, frequency, duration and intensity)," and "I will continue to practice physical exercise in the next six months as I currently practice or in a very similar way (same type, frequency, duration and intensity)." A 7-point Likert scale anchored from 1- "absolutely not" to 7- "absolutely yes" was used to respond to these items.

\subsubsection{Exercise persistence}

Researchers encoded the participants' persistence based on a computer record gym attendance system. The participants' exercise persistence was evaluated based on a similar weekly frequency at the gym compared to the self-reported levels of frequency of each participant at the beginning of the assessment, during 6 months. 
The participants' persistence was coded as 1 ("persistent") if they maintained their self-reported frequency. Participants who have quit, who have not returned to practice, or had a significantly different weekly exercise frequency compared to what has been self-reported were coded 0 ("non-persistent"). Gucciardi and Jackson ${ }^{31}$ and Sarrazin et al ${ }^{32}$ have also used this dichotomic coding system in the past, presenting reliable results. The 6-month criterion used in this study was based on the following: (a) individuals who exercise regularly for at least six months have lower intention to dropout, ${ }^{33}$ and (b) dropout rates are approximately $50 \%$ in the first 6 months, thus stabilizing from this period onwards. ${ }^{34}$

\section{$2.3 \quad$ Statistical analysis}

Data from questionnaires with missing values $\leq 5 \%$ were imputed using the multiple imputation (MI) method according to Allison ${ }^{35}$ using IBM SPSS Statistics v23. Participants were excluded for analysis if they had missing values $>5 \%$. Possible univariate $(z>3.00)$ and multivariate $\left(D^{2}=\mathrm{p} 1<0.001, \mathrm{p} 2<0.001\right)$ outliers were also excluded from analysis. ${ }^{36}$

The mean, standard deviations, bivariate correlations, and composite reliability were observed for all study variables. Next, a two-step maximum likelihood (ML) approach following Kline ${ }^{37}$ recommendations was performed using IBM SPSS AMOS v23. First, a CFA was conducted to test the psychometric properties of the model. Average variance extracted (AVE) to evaluate convergent validity was calculated, and scores $\geq 0.50$ were defined as acceptable. ${ }^{38}$ Discriminant validity was confirmed when AVE scores were higher than the squared correlation across constructs of the measurement model. ${ }^{36,38}$ Second, a structural equation model (SEM) to test model fit was performed, and direct and indirect effects among all constructs were analyzed. Analysis of both CFA and SEM was performed according to the traditional absolute and incremental indexes: comparative fit index (CFI), Tucker-Lewis index (TLI), standard root mean residual (SRMR), root mean square error of approximation (RMSEA), and its confidence interval of $90 \%$ (CI: 90\%). For these indexes, recommendations from several authors ${ }^{36,38,39}$ were followed: CFI and $\mathrm{TLI} \geq 0.90$, SRMR and RMSEA $\leq 0.8$.

Regarding the parameters to be estimated (ie, 72 parameters), Kline ${ }^{37}$ recommends a 10:1 ratio (participants per parameter to be estimated), which was not performed in present study. However, according to Worthington and Whittaker ${ }^{40}$ and Hair and Black, ${ }^{38}$ a 5:1 ratio is acceptable to conduct CFA and SEM analyses, as used in this study. As a complementary sample size analysis, G*Power v3.1 ${ }^{41}$ software was used to calculate the minimum required sample size. Past studies ${ }^{42,43}$ have used this program as a way of determining sample size when the number of participants did not adhere to the recommended 10:1 ratio or the minimum 5:1 ratio. Thus, as a complementary analysis, $G *$ Power 3.1 was used to calculate the required sample size ${ }^{41}$ including the following parameters: anticipated effect size of $f^{2}=0.01, \alpha=0.05$, and statistical power $=0.95$, suggesting a minimum of 287 participants, which was respected in this study.

\subsection{1 | Serial mediation analysis}

To further understand the proposed model, serial mediation procedures according to Hayes ${ }^{44}$ recommendations were performed using SPSS PROCESS v3.3. This analysis adds details about understanding the mediator's role on the outcome variable.

Considering the hypothetical SEM previously analyzed, no pre-defined serial mediation model presented by SPSS PROCESS v3.3 could adequately analyze the direct and indirect effects accounting for other possible interactions. Therefore, based on model 6 in SPSS PROCESS v3.3, which allows several serial mediators analyses, a specific matrix and syntax in order to account for this issue was created. Examining mediation model I (BPN satisfaction, autonomous motivation, enjoyment, and intention) and mediation model II (BPN frustration, controlled motivation, enjoyment, and intention), both models contained four serial mediators, and covariances were integrated along with specific mediation paths in order to account for possible variable interactions, better representing the hypothetical model. Adding covariances without restricted path interactions in mediation models may affect all mediators and dependent variables and possibly reduce model understanding. ${ }^{44}$ Considering the theoretical implications and previous SEM model specifications, in model I, thwarting interpersonal behaviors (on all mediators and the dependent variable), BPN frustration (on controlled motivation, enjoyment, intention to continue exercising and the dependent variable), and controlled motivation (on enjoyment, intention to continue exercising, and the dependent variable) were defined as specific path covariates. In model II, the same approach was used with the bright side of motivation constructs. Bootstrap with 10000 samples was used, and the confidence interval (95\%) estimate was calculated. In the case of mediation, the ratio of total indirect effect over total effect $\left(P_{\mathrm{M}}\right)$ will be presented to quantify the strength of mediation. ${ }^{45}$

\subsection{2 | Multigroup analysis}

In terms of multigroup analysis, our aim was to test structural invariance between male and female exercisers and to 
assess model adequacy in groups with different characteristics; to this end, an analysis was performed in line with previous authors. ${ }^{36,46}$ First, we analyzed if the structural model presented a good fit to the data in male and female exercisers. Multigroup analysis was then performed according to Byrne, ${ }^{36}$ comparing the unconstrained model with the constrained models in terms of measurement weights, structural weights, measurement intercepts, structural residuals, and measurement residuals. Invariance assumptions were verified through the differences in CFI $(\triangle \mathrm{CFI})$ using $<0.01$ as cutoff values. ${ }^{36,46}$ IBM SPSS AMOS v23 to perform multigroup analysis was used.

\section{$3 \quad$ RESULTS}

\section{1 | Preliminary analysis}

The data were imputed in five participants who showed missing values $<5 \%$ in all questionnaires; thus, no univariate or multivariate outliers were found. Descriptive statistics indicated no deviations from normality (skewness ranged from -1.98 to +1.98 ; kurtosis ranged from -7 to $+7)$. However, Mardia's coefficient for multivariate kurtosis exceeded expected values ( $>5)$. Therefore, a BollenStine (B-S) of 2000 samples for the subsequent analysis was imputed following Nevitt and Hancock ${ }^{47}$ recommendations. Last, to verify possible collinearity issues, the variance inflation factor (VIF) was analyzed. The VIF results showed scores below 10 , rejecting the hypothesis of collinearity issues and ensuring the conditions to test the regression model. ${ }^{38}$ Regarding bivariate correlations, bright side motivational constructs were positively correlated with each other, as well as with enjoyment, intention to continue exercising, and exercise persistence. Conversely, dark side motivational constructs were positively and significantly correlated with each other and negatively associated with enjoyment, intention to continue exercising, and exercise persistence. For details, see Table 1.

According to electronic records, of all evaluated participants, 472 participants (82\%) exercised at least 2 times a week $(\mathrm{M}=2.89 ; \mathrm{SD}=0.98)$ during the 6 months after initial assessment, while the other 103 participants in the present study withdrew from exercising during the first 2-4 months after completing questionnaires at initial assessment.

\subsection{Confirmatory factorial analysis and structural equation model}

Results from the CFA showed that the model fit the data: $\left[\chi^{2}(370)=1496.708, \chi^{2} / \mathrm{df}=4.05 ; \mathrm{B}-\mathrm{S} P<.001\right.$, $\mathrm{CFI}=0.907, \mathrm{TLI}=0.901, \mathrm{SRMR}=0.056, \mathrm{RMSEA}=0.073$ (CI 90\% $=0.063,0.083)]$. Convergent and discriminant validity was achieved, and composite reliability reported scores above acceptable, except for controlled motivation (see Table 2). As in the CFA, the SEM model showed acceptable fit: $\left[\chi^{2}(393)=2484.994, \chi^{2} / \mathrm{df}=6.323\right.$; B-S $P<.001, \mathrm{CFI}=0.908, \mathrm{TLI}=0.900, \mathrm{SRMR}=0.0754$, RMSEA $=0.071($ CI 90\% $=0.067,0.075)]$. As seen in Figure 1, all factor weights were above the cutoff values, except for perceived autonomy thwarting and introjected regulation.

TA B LE 1 Mean, standard deviation, and correlations between constructs

\begin{tabular}{|c|c|c|c|c|c|c|c|c|c|c|c|}
\hline & \multirow[b]{2}{*}{$\mathbf{M}$} & \multirow[b]{2}{*}{ SD } & \multicolumn{9}{|l|}{$r$} \\
\hline & & & 1 & 2 & 3 & 4 & 5 & 6 & 7 & 8 & 9 \\
\hline $\begin{array}{l}\text { 1. Perceived Supportive } \\
\text { Behaviors }\end{array}$ & 4.58 & 0.64 & 1 & & & & & & & & \\
\hline $\begin{array}{l}\text { 2. Perceived Thwarting } \\
\text { Behaviors }\end{array}$ & 1.13 & 0.82 & $-0.72 * *$ & 1 & & & & & & & \\
\hline 3. BPN Satisfaction & 3.13 & 0.42 & $0.51 * *$ & $-0.73 * *$ & 1 & & & & & & \\
\hline 4. BPN Frustration & 0.41 & 0.23 & $-0.39 * *$ & $0.78 * *$ & $-0.85 * *$ & 1 & & & & & \\
\hline $\begin{array}{l}\text { 5. Autonomous } \\
\text { Motivation }\end{array}$ & 2.05 & 0.29 & $0.56^{* *}$ & $-0.42 * *$ & $0.57 * *$ & $-0.63 * *$ & 1 & & & & \\
\hline $\begin{array}{l}\text { 6. Controlled } \\
\text { Motivation }\end{array}$ & 0.74 & 0.41 & $-0.66^{* *}$ & $0.42 * *$ & $-0.76^{* *}$ & $0.46 * *$ & $-0.66^{* *}$ & 1 & & & \\
\hline 7. Enjoyment & 6.85 & 1.07 & $0.55^{* *}$ & $-0.27 * *$ & $0.32 * *$ & $-0.26 * *$ & $0.70 * *$ & $-0.48 * *$ & 1 & & \\
\hline 8. Intention & 4.32 & 0.64 & $0.18 * *$ & $-0.09 *$ & $0.10 *$ & $-0.10^{*}$ & $0.19 * *$ & $-0.17 * *$ & $0.41 * *$ & 1 & \\
\hline 9. Persistence & - & - & $0.61 * *$ & $-0.39 * *$ & $0.39 * *$ & $-0.38 * *$ & $0.67 * *$ & $-0.51 * *$ & $0.86^{* *}$ & $0.33 * *$ & 1 \\
\hline
\end{tabular}

Abbreviations: BPN, basic psychological needs; M, mean; $r$, correlation matrix; SD, standard deviation. 
TA B LE 2 Composite reliability, average mean extracted, and squared correlations between constructs

\begin{tabular}{|c|c|c|c|c|c|c|c|c|c|c|c|}
\hline & \multirow[b]{2}{*}{ CR } & \multirow[b]{2}{*}{ AVE } & \multicolumn{9}{|l|}{$r^{2}$} \\
\hline & & & 1 & 2 & 3 & 4 & 5 & 6 & 7 & 8 & 9 \\
\hline $\begin{array}{l}\text { 1. Perceived Supportive } \\
\text { Behaviors }\end{array}$ & 0.84 & 0.80 & 1 & & & & & & & & \\
\hline $\begin{array}{l}\text { 2. Perceived Thwarting } \\
\text { Behaviors }\end{array}$ & 0.70 & 0.63 & 0.43 & 1 & & & & & & & \\
\hline 3. BPN Satisfaction & 0.79 & 0.72 & 0.35 & 0.11 & 1 & & & & & & \\
\hline 4. BPN Frustration & 0.81 & 0.77 & 0.19 & 0.43 & 0.49 & 1 & & & & & \\
\hline $\begin{array}{l}\text { 5. Autonomous } \\
\text { Motivation }\end{array}$ & 0.80 & 0.76 & 0.25 & 0.13 & 0.35 & 0.25 & 1 & & & & \\
\hline 6. Controlled Motivation & 0.57 & 0.51 & 0.10 & 0.50 & 0.13 & 0.62 & 0.33 & 1 & & & \\
\hline 7. Enjoyment & 0.94 & 0.84 & 0.26 & 0.05 & 0.19 & 0.08 & 0.42 & 0.05 & 1 & & \\
\hline 8. Intention & 0.93 & 0.93 & 0.03 & 0.01 & 0.01 & 0.01 & 0.03 & 0.01 & 0.15 & 1 & \\
\hline 9. Persistence & - & - & 0.32 & 0.13 & 0.22 & 0.13 & 0.40 & 0.13 & 0.71 & 0.10 & 1 \\
\hline
\end{tabular}

Abbreviations: AVE, average variance extracted; BPN, basic psychological needs; CR, composite reliability; $r^{2}$, squared correlation matrix.

Positive and significant predictions were observed among all the constructs (see Table 3), except for perceived supportive behavior $\rightarrow$ BPN satisfaction; perceived supportive behavior $\rightarrow$ BPN frustration; and perceived thwarting behavior $\rightarrow$ BPN satisfaction. The results display several indirect effects between constructs (see Table 4), enjoyment being the variable with the highest indirect effect on exercise persistence. Looking at explained variance, intentions to continue exercising explained variance was $11 \%$ in exercise persistence, and SEM model explained variance was $14 \%$ in exercise persistence. To examine construct interactions on persistence in more detail, mediation analysis was conducted.

\subsection{Serial mediation analysis}

In Figure 2, it is possible to observe the serial mediation effects of different constructs on exercise persistence. In model $\mathrm{I}$, a full mediation appears between supportive behaviors and exercise persistence ( $\left.\beta=0.45[0.34-0.53] ; P_{\mathrm{M}}=0.90\right)$. Additionally, enjoyment presented the highest effect on persistence $(\beta=0.83[0.80-0.86])$. As for mediation sequential influence, autonomous motivation had the highest effect on enjoyment ( $\beta=0.85$ [0.72-0.99]).

In model II, no mediation appears between thwarting behaviors and exercise persistence $(\beta=0.03[-0.06$ to 0.01$]$ ), and motivational variables did not have a

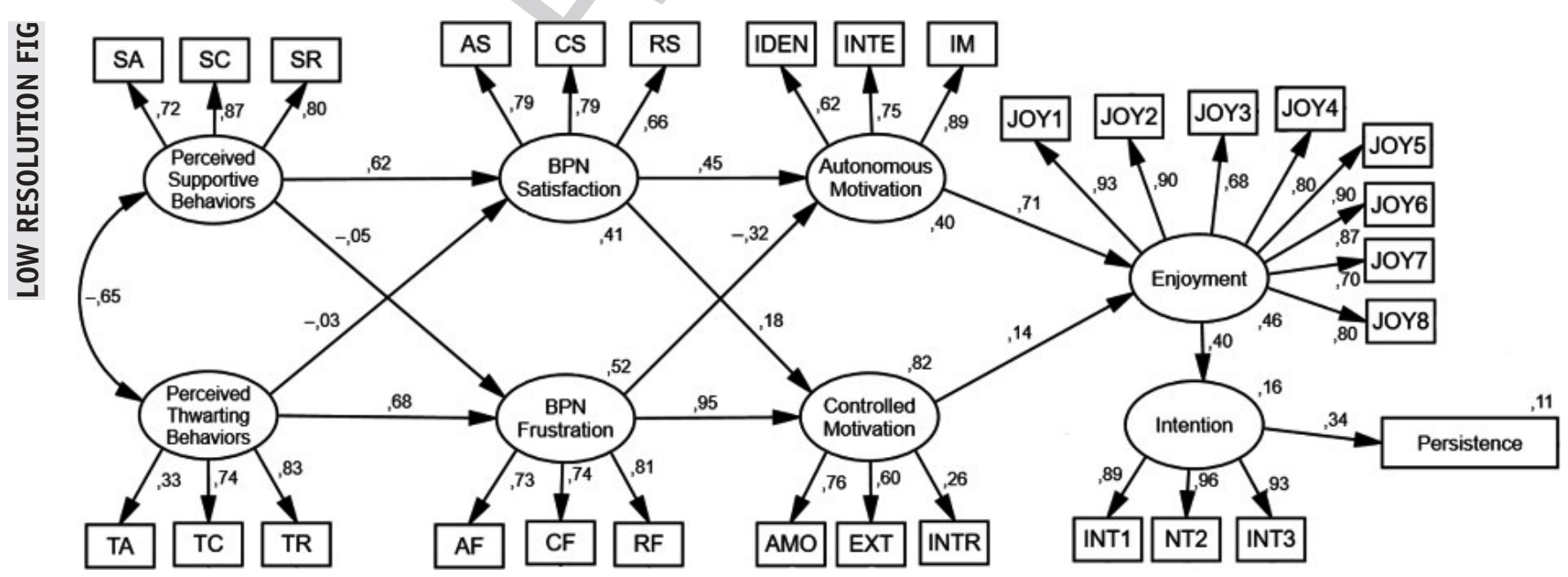

5 FI G URE 1 Structural equation model. AF, Autonomy Frustration; AMO, Amotivation; AS, Autonomy Satisfaction; CF, Competence Frustration; CS, Competence Satisfaction; EXT, External regulation; IDEN, Identified regulation; IM, Intrinsic Motivation; INT1-3, items regarding intention to continue exercising; INTE, Integrated Regulation; INTR, Introjected regulation; JOY1-8, items regarding enjoyment; RF, Relatedness Frustration; RS, Relatedness Satisfaction; SA, Perceived Autonomy Support; SC, Perceived Competence Support; SR, Perceived Relatedness Support s; TA, Perceived Autonomy Thwarting; TC, Perceived Competence Thwarting; TR, Perceived Relatedness Thwarting 
significant effect on persistence. Nevertheless, the individual path between enjoyment and exercise persistence presented a significant effect $(\beta=0.83[0.80-0.86])$, as did the individual path between intention and persistence $(\beta=0.04$ [0.01-0.07]).

\section{4 | Multigroup analysis}

The structural model had adequate fit in male $\left[\chi^{2}(393)=1458.796, \chi^{2} / \mathrm{df}=3.712 ;\right.$ B-S $P<.001$, $\mathrm{CFI}=0.915, \quad$ TLI $=0.904, \quad$ SRMR $=0.081$, RMSEA $=0.076(\mathrm{CI} 90 \%=0.070,0.082)]$ and female exercisers $\left[\chi^{2}(393)=1430.063, \chi^{2} / \mathrm{df}=3.639\right.$; B-S $P<.001$, $\mathrm{CFI}=0.906, \mathrm{TLI}=0.899, \mathrm{SRMR}=0.079, \mathrm{RMSEA}=0.067$ $($ CI $90 \%=0.062,0.073)]$. The results showed model invariance between both groups, since invariance assumptions were met (see Table 5).

\section{DISCUSSION}

The aim of the present study was to test an extended HMIEM, ${ }^{4}$ exploring the relationship between the bright and dark sides of motivation constructs on enjoyment, intention to continue exercising, and exercise persistence after a 6-month time period. This analysis was conducted according to a previously proposed hypothesis. ${ }^{9,10}$
Examining correlations, positive and significant associations were observed among bright side motivational determinants, enjoyment, intention to continue, and persistence. On the other hand, dark side motivational constructs were positively and significantly correlated with each other, and negatively with bright side constructs, enjoyment, intention, and persistence. These results have been theoretically ${ }^{2}$ and systematically supported in exercise settings. 3,48

\subsection{Confirmatory factor analysis and structural equation model}

The model for CFA and SEM had a good fit to the data according to several authors. ${ }^{36,38}$ In addition, convergent and discriminant validity was achieved, and composite reliability was above the cutoff values, except for controlled motivation (see Table 2 and Figure 1). Perceived autonomy thwarting and introjected regulation had factor weights $<0.50$ and should have been excluded from the model according to Hair et al. ${ }^{38}$ However, these items increased content validity, and their exclusion did not improve model fit. In addition, Hair and Black ${ }^{38}$ suggest that rules of thumb are only guidelines and that if the overall measurement model exhibit good fit, then the items should be maintained. The hypothesis for perceived autonomy thwarting's low factor weight could be explained by participants' gym activities.

\begin{tabular}{|c|c|c|c|c|}
\hline Path & $\boldsymbol{\beta}$ & $R^{2}$ & CI 95\% & $P$ \\
\hline $\begin{array}{l}\text { Perceived Supportive Behaviors } \rightarrow \text { BPN } \\
\text { Satisfaction }\end{array}$ & 0.620 & 0.384 & $-0.488 / 0.815$ & .195 \\
\hline $\begin{array}{l}\text { Perceived Supportive Behaviors } \rightarrow \text { BPN } \\
\text { Frustration }\end{array}$ & -0.052 & 0.002 & $-0.334 / 0.217$ & .650 \\
\hline $\begin{array}{l}\text { Perceived Thwarting Behaviors } \rightarrow \text { BPN } \\
\text { Satisfaction }\end{array}$ & -0.028 & 0.000 & $-0.158 / 0.192$ & .728 \\
\hline $\begin{array}{l}\text { Perceived Thwarting Behaviors } \rightarrow \text { BPN } \\
\text { Frustration }\end{array}$ & 0.684 & 0.467 & $0.328 / 0.797$ & .002 \\
\hline $\begin{array}{l}\text { BPN Satisfaction } \rightarrow \text { Autonomous } \\
\text { Motivation }\end{array}$ & 0.450 & 0.202 & $0.299 / 0.568$ & .003 \\
\hline $\begin{array}{l}\text { BPN Satisfaction } \rightarrow \text { Controlled } \\
\text { Motivation }\end{array}$ & 0.183 & 0.033 & $0.062 / 0.378$ & .017 \\
\hline $\begin{array}{l}\text { BPN Frustration } \rightarrow \text { Autonomous } \\
\text { Motivation }\end{array}$ & -0.323 & 0.104 & $-0.468 /-0.203$ & .001 \\
\hline $\begin{array}{l}\text { BPN Frustration } \rightarrow \text { Controlled } \\
\text { Motivation }\end{array}$ & 0.949 & 0.900 & $0.855 / 0.958$ & .002 \\
\hline Autonomous Motivation $\rightarrow$ Enjoyment & 0.711 & 0.505 & $0.643 / 0.775$ & .001 \\
\hline Controlled Motivation $\rightarrow$ Enjoyment & 0.142 & 0.020 & $0.051 / 0.241$ & .012 \\
\hline Enjoyment $\rightarrow$ Intention & 0.404 & 0.163 & $0.336 / 0.468$ & .001 \\
\hline Intention $\rightarrow$ Persistence & 0.336 & 0.112 & $0.271 / 0.399$ & .001 \\
\hline
\end{tabular}

TA B L E 3 Path estimates direct effect among constructs

Abbreviations: $\beta$, estimate; BPN, basic psychological needs; CI 95\%, confidence interval; $P$, level of significance; $R^{2}$, explained variance. 
Since exercisers participated in several different activities (eg, indoor cycling, recreational bodybuilding, or personal training), their perception of fitness instructors' behaviors could vary to some degree. For example, fitness group instructors execute their preprogrammed classes, and all gym exercisers are encouraged to follow their movements. However, in the cardio/resistance training room, participants exercise according to their own training program, thus having more freedom to select which exercises to perform, in which order and when to perform them. Looking at introjected regulation, the results could be explained by the new theoretical advances made in distinguishing this regulation as more controlled (eg, "I must go to the gym to increase my physical fitness") or more autonomous (eg, "I am going to work out because I want to increase my physical fitness") regulated. Past studies ${ }^{49,50}$ suggest that introjected regulation can be perceived as approach (ie, more proximal to identified regulation) or as avoidance (ie, more proximal to external regulation), resulting in different outcomes. This difference, in turn, could have been accounted for controlled motivation's low composite reliability score.

\section{2 | Mediation analysis}

The results in this study displayed that bright side and, in part, dark side motivational constructs had some indirect effects on persistence. Since significant indirect effects were found between variables under analysis, Hair et $\mathrm{al}^{29}$ suggest the need to analyze mediation to support the observed predictions. In addition, to corroborate with SDT universality tenets
TA B LE 4 Path estimates indirect effects among constructs

\begin{tabular}{|c|c|c|c|c|}
\hline Path & $\boldsymbol{\beta}$ & $R^{2}$ & CI 95\% & $P$ \\
\hline $\begin{array}{l}\text { Perceived Supportive } \\
\text { Behaviors } \rightarrow \text { Autonomous Motivation }\end{array}$ & 0.296 & 0.087 & $-0.598 / 0.385$ & .234 \\
\hline $\begin{array}{l}\text { Perceived Supportive } \\
\text { Behaviors } \rightarrow \text { Controlled Motivation }\end{array}$ & 0.064 & 0.004 & $-0.171 / 0.442$ & .593 \\
\hline $\begin{array}{l}\text { Perceived Supportive } \\
\text { Behaviors } \rightarrow \text { Enjoyment }\end{array}$ & 0.219 & 0.047 & $-0.302 / 0.309$ & .193 \\
\hline $\begin{array}{l}\text { Perceived Supportive } \\
\text { Behaviors } \rightarrow \text { Intention }\end{array}$ & 0.089 & 0.007 & $-0.086 / 0.131$ & .163 \\
\hline $\begin{array}{l}\text { Perceived Supportive } \\
\text { Behaviors } \rightarrow \text { Persistence }\end{array}$ & 0.030 & 0.000 & $-0.086 / 0.049$ & .134 \\
\hline $\begin{array}{l}\text { Perceived Thwarting } \\
\text { Behaviors } \rightarrow \text { Autonomous Motivation }\end{array}$ & -0.234 & 0.054 & $-0.356 /-0.085$ & .019 \\
\hline $\begin{array}{l}\text { Perceived Thwarting } \\
\text { Behaviors } \rightarrow \text { Controlled Motivation }\end{array}$ & 0.644 & 0.414 & $0.352 / 0.684$ & .002 \\
\hline $\begin{array}{l}\text { Perceived Thwarting } \\
\text { Behaviors } \rightarrow \text { Enjoyment }\end{array}$ & -0.075 & 0.005 & $-0.691 / 0.003$ & .111 \\
\hline $\begin{array}{l}\text { Perceived Thwarting } \\
\text { Behaviors } \rightarrow \text { Intention }\end{array}$ & -0.030 & 0.000 & $-0.298 / 0.000$ & .098 \\
\hline $\begin{array}{l}\text { Perceived Thwarting } \\
\text { Behaviors } \rightarrow \text { Persistence }\end{array}$ & -0.010 & 0.000 & $-0.103 / 0.000$ & .094 \\
\hline BPN Satisfaction $\rightarrow$ Enjoyment & 0.346 & 0.119 & $0.242 / 0.440$ & .001 \\
\hline BPN Satisfaction $\rightarrow$ Intention & 0.140 & 0.019 & $0.094 / 0.185$ & .001 \\
\hline BPN Satisfaction $\rightarrow$ Persistence & 0.047 & 0.002 & $0.028 / 0.070$ & .001 \\
\hline BPN Frustration $\rightarrow$ Enjoyment & -0.095 & 0.009 & $-0.220 / 0.003$ & .113 \\
\hline BPN Frustration $\rightarrow$ Intention & -0.038 & 0.001 & $-0.091 / 0.001$ & .114 \\
\hline BPN Frustration $\rightarrow$ Persistence & -0.013 & 0.000 & $-0.034 / 0.000$ & .100 \\
\hline Autonomous Motivation $\rightarrow$ Intention & 0.057 & 0.003 & $0.223 / 0.339$ & .001 \\
\hline Autonomous Motivation $\rightarrow$ Persistence & 0.019 & 0.000 & $0.066 / 0.132$ & .001 \\
\hline Controlled Motivation $\rightarrow$ Intention & 0.287 & 0.082 & $0.023 / 0.103$ & .008 \\
\hline Controlled Motivation $\rightarrow$ Persistence & 0.097 & 0.009 & $0.008 / 0.038$ & .008 \\
\hline Enjoyment $\rightarrow$ Persistence & 0.136 & 0.018 & $0.093 / 0.185$ & .001 \\
\hline
\end{tabular}

Abbreviations: $\beta$, estimate; BPN, basic psychological needs; CI 95\%, confidence interval; $P$, level of significance; $R^{2}$, explained variance. 


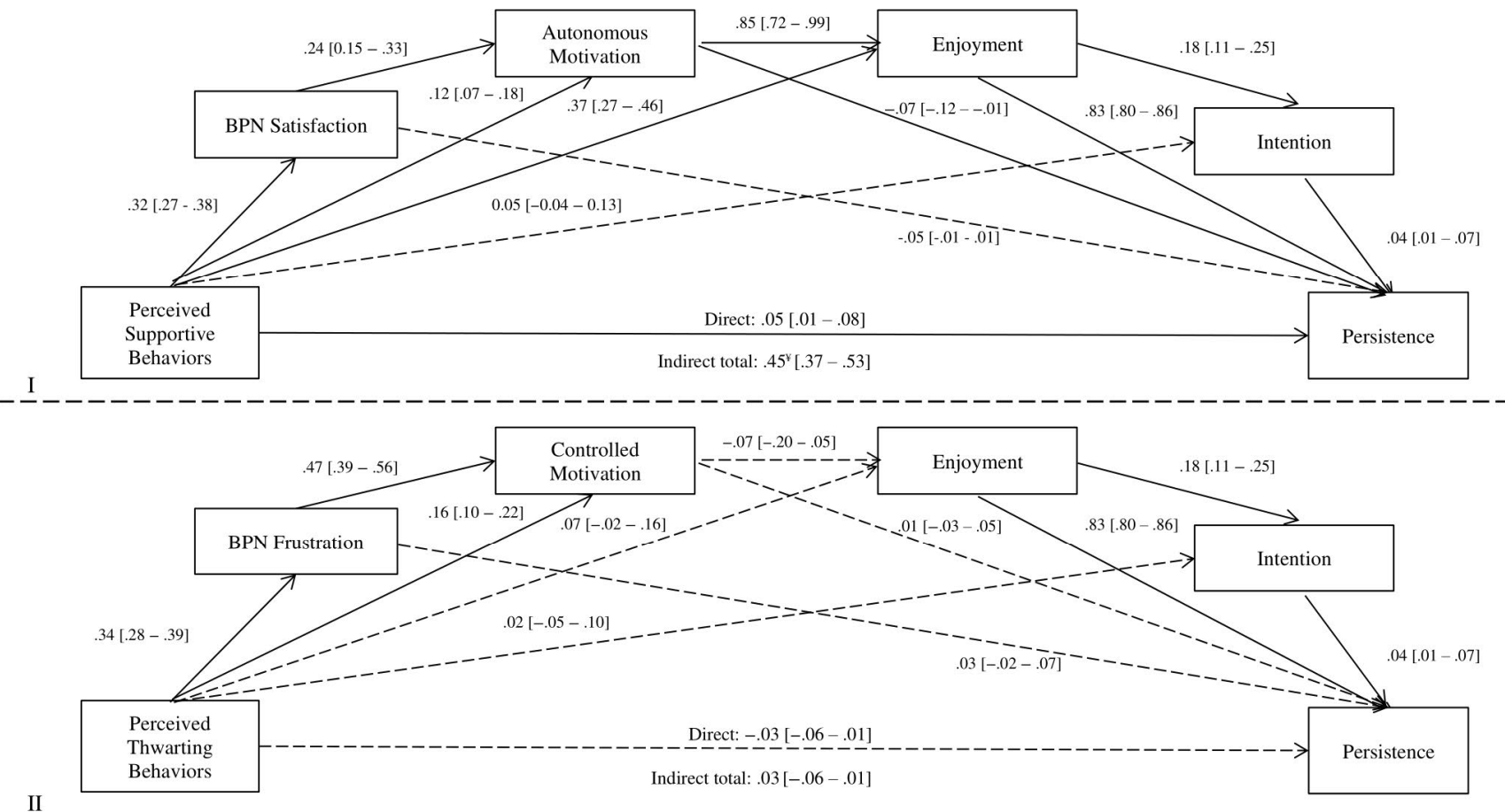

F IG U RE 2 Serial mediation model I—controlling for dark side of motivation constructs — and model II—controlling for

bright side of motivation constructs. $* * *<.001 ; ¥=95 \%$ CI estimate indicate a significant indirect effect; significant effect $\rightarrow$; nonsignificant effect $-\rightarrow$; BPN $=$ Basic Psychological Needs; unobserved paths: BPN Satisfaction $-\rightarrow$ Enjoyment $=0.11[-0.04-0.26]$; BPN Satisfaction $-\rightarrow$ Intention $=0.06[-0.07-0.19]$; Autonomous Motivation $\rightarrow$ Intention $=0.17$ [0.03-0.30]; BPN Frustration $--\rightarrow$ Enjoyment $=-0.08$ $[-0.22-0.06]$; BPN Frustration $--\rightarrow$ Intention $=-0.04[-.17-0.08]$; Controlled Motivation $-\rightarrow$ Intention $=-0.07[-0.18-0.04]$

TABLE 5 Structural invariance analysis between male and female

\begin{tabular}{llllccccc} 
& $\chi^{2}$ & df & $\chi^{\mathbf{2} / \mathbf{d f}}$ & $\Delta \boldsymbol{\chi}^{\mathbf{2}}$ & $\Delta$ df & $\boldsymbol{P}$ & CFI & $\Delta$ CFI \\
\hline Unconstrained Model & 2888.913 & 786 & 3.675 & - & - & $<.001$ & 0.906 & - \\
\hline Measurement Weights & 2904.335 & 808 & 3.594 & 15.422 & 22 & $<.001$ & 0.907 & 0.001 \\
\hline Structural Weights & 2909.039 & 819 & 3.552 & 20.126 & 33 & $<.001$ & 0.907 & 0.001 \\
\hline Structural Covariances & 2917.474 & 822 & 3.549 & 28.561 & 36 & $<.001$ & 0.906 & 0.000 \\
\hline Structural Residual & 2931.360 & 828 & 3.540 & 42.447 & 42 & $<.001$ & 0.906 & 0.000 \\
\hline Measurement Residual & 2979.550 & 858 & 3.566 & 90.637 & 72 & $<.001$ & 0.901 & 0.005 \\
\hline
\end{tabular}

Abbreviations: $\Delta \chi^{2}$, differences in qui-square; $\Delta \mathrm{CFI}$, differences in CFI; $\Delta \mathrm{df}$, differences in df; CFI, comparative fit index; df, degrees of freedom; $P$, level of 7 significance; $\chi^{2}$, qui-square.

and HMIEM's causal sequence, it is important to measure the effect of each variable on this contextual setting.

In serial mediation models, the bright side motivational model presented a full mediation $(\beta=0.45$ [0.34-53]; $P_{\mathrm{M}}=0.90$ ), which reinforces this study's previous findings regarding similar model testing and mediators' influence on persistence. In this model, only the enjoyment mediator presented significant positive indirect effects on persistence ( $\beta=0.30$ [0.22-0.39]). However, the sequential mediators' influence across the model is always significant (supportive behaviors $\rightarrow$ BPN satisfaction $\rightarrow$ autonomous motivations $\rightarrow$ enjoyment $\rightarrow$ intention $\rightarrow$ persistence), which aligns with the SDT framework and previously reported studies on bright side constructs on enjoyment, intention, and persistence. ${ }^{9,15}$ Curiously, the dark side of the motivation model did not present significant direct or indirect effects on persistence. Even enjoyment as an isolated mediator showed a high regression score with persistence $(\beta=0.83$ [0.80-0.86]) but decreased its indirect effect on persistence in this model $(\beta=0.06[-0.03-0.14])$ and does not account for an indirect significant effect. Moreover, despite the absence of BPN frustration and controlled motivation's significant indirect effects on persistence, it is possible to observe that perceived thwarting behavior had positive significant effects on these mediators, supporting expected sequential path interactions. ${ }^{3}$ This observation could be in part responsible for the lower/absence of mediating effects of enjoyment. 


\section{3 | Multigroup analysis}

The structural model displayed invariance $(\Delta \mathrm{CFI}<0.01)$ between male and female exercisers, meaning that both similarly perceive the impact of motivational determinants, enjoyment, and intention to continue exercising on exercise persistence. To the best of our knowledge, no study has ever tested between genders the HMIEM sequence, or structural invariance, much less the current hypothesized model in the exercise context. Nevertheless, existing studies testing multigroup analysis on motivational determinants have shown that male and female individuals experience exercise participation in a similar manner, ${ }^{51}$ regulate their behavior toward exercise equally, ${ }^{26}$ and perceive enjoyment in a similar way when exercising. ${ }^{29}$

\section{4 | Overall considerations}

Examining the overall hypothesized model, the current research adds new insights into how the HMIEM can be extended, considering both sides of motivation on emotional, cognitive, and behavioral outcomes. Starting with the bright side of motivation sequence, supportive interpersonal behaviors had a significant indirect effect on autonomous motivation via BPN satisfaction, leading to significant estimates on enjoyment and higher levels on intention to continue exercising and ultimately resulting in increased rates of exercise persistence. The present results support previous studies considering only parts of this sequence, specifically the predictions of interpersonal behaviors on basic needs satisfaction, ${ }^{12,13,52}$ the effect of basic need satisfaction on behavioral regulation, ${ }^{8,14}$ behavioral regulation on enjoyment, ${ }^{16}$ enjoyment on intention to continue exercising, ${ }^{5,9}$ and ultimately the impact of intentions toward exercising in the future on persistence. ${ }^{6}$ BPN satisfaction had an indirect effect on enjoyment via autonomous motivation, showing that the satisfaction of basic needs is essential for promoting autonomous motivation, proving itself to be a strong predictor of positive outcomes, including enjoyment, and thus corroborating past literature..$^{9,10,53}$

As for the dark side of motivation, our results corroborate those of Rocchi and Pelletier, ${ }^{52}$ showing that perceived thwarting behaviors predicted basic needs frustration. In turn, as current results show, BPN frustration was positive and significantly related to controlled motivation, explaining that when people feel controlled by the environment, they tend to act on behavior for controlled reasons (eg, "I exercise because my exercise instructors says so"). Similar results have been shown in the contexts of exercise, ${ }^{14}$ sport, ${ }^{8}$ and physical education. ${ }^{54}$ Gunnel et $\mathrm{al}^{55}$ have shown that when individuals perceive BPN frustration, negative outcomes are more likely to occur. Interestingly, contrarily to past theoretical literature associating controlled motivation with diminished function and negative outcomes, ${ }^{56}$ a significant positive direct effect on enjoyment was found. Nevertheless, no mediation effects were found on the dark side of motivation analysis. This finding should be interpreted with caution, as there might have been interpretation issues in gym exercisers' differing approaches and avoidance of introjected regulation. More research is warranted to measure the effect of controlled regulations, as a composite score or as independent constructs, on emotional outcomes.

Regarding intention, although it had a significant effect on exercise persistence, it only explained $11 \%$ of variance. Hence, the structural model overall, considering direct and indirect effects, explained $14 \%$ of variance. This result shows that having intentions to continue acting on a behavior does not always translate into the behavior itself, as explained by Hagger and Chatzisarantis. ${ }^{57}$ In addition, regarding the total number of individuals who exercised during the 6 months after their self-reported initial assessment, the results showed that $82 \%$ maintained a similar exercise participation. We suspect that these percentages of exercise persistence could be related to the high levels of enjoyment perceived by exercisers and/ or because of their training experience ( $<6$ months). Current results show that enjoyment had the strongest effect on exercise persistence, explaining the need to feel pleasure and joy when acting on a certain behavior as a way of maintaining its commitment in the long term. The results corroborate the notion that engaging in regular exercise because of volitional choice and satisfaction is crucial as a way of persisting. Nevertheless, emotional outcomes have not received enough attention in terms of their prediction of intention, specifically in an exercise context, and more studies are warranted.

The present results are relevant, since they corroborate previous literature, ${ }^{9,16,22}$ showing significant interaction across motivational determinants, enjoyment, and intention on behavior persistence, even in the context under analysis. In addition, it was demonstrated that enjoyment is a strong predictor for promoting physical exercise persistence. Exercise instructors should create fun and pleasurable environments. Understanding what makes people enjoy exercising in gyms and health clubs, as well as how to generate an enjoyable atmosphere with others, seems crucial to increasing their persistence in exercising. For example, promoting exercise variability in training sessions according to exercisers' feedback and suggestions could increase individuals' exercising commitment. ${ }^{58}$ Fitness professionals should generate effective questions during training sessions in order to be perceived as attentive and mindful.

\section{5 $\quad$ Perspective}

Fitness professionals should endorse supportive behaviors when interacting with gym clients and avoid using negative feedback; fitness professionals should also not pressure 
clients to perform only preprogrammed exercises. Instead, gym clients should be encouraged to improve their technique, and exercisers should receive some volitional choice of which exercises to perform that are aligned with the main structure of the individual's exercise program. In fact, in the present study, in terms of the bright and dark sides of motivation, enjoyment always has the same tendency. It might be hypothesized that even exercisers who train for external reasons or under self-imposed pressure can still experience pleasure when exercising. Nevertheless, in the dark side sequence, the other constructs had no relevant effect on exercise persistence, contrary to the bright side sequence. This result suggests that enjoyment, as an isolated predictor, cannot promote behavior persistence. Exercisers must experience supportive behaviors in order to induce greater levels of enjoyment, eventually leading to exercise persistence in the long run.

\section{CONCLUSION}

As empirically demonstrated, supportive interpersonal behaviors are key aspects to successfully promote BPN satisfaction, and hence autonomous motivation, enjoyment, intention to continue exercising, and ultimately exercise persistence in both male and female individuals.

The complexity of the hypothesized model considering the bright and dark sides of motivation, enjoyment, intention to continue exercising, and exercise persistence provides professionals with the crucial tools to promote exercise participation. According to current research, exercisers should experience enjoyment when exercising, as a way of maintaining exercise participation for at least 6 months.

\section{$5.1 \mid$ Limitations}

A limitation of the present study that should be acknowledged is that we measured SDT constructs, enjoyment, and intention to continue exercising at initial assessment and exercise persistence 6 months after. It would be interesting in future studies to explore the extent to which these constructs fluctuate over time and how this influences exercise persistence. Likewise, assessing persistence over a longer period of time (eg, 1 year) could be of interest in measuring the impact of motivational determinants. In addition, since this was the first study to consider both the bright and dark sides of motivation determinants, as well as enjoyment, intention to continue exercising, and exercise persistence in an exercise context, further studies are needed to better understand this dynamic. Future studies should also test our hypothesized model under similar contexts (eg, sports) and in different cultures.

Composite scores had to be created in order to reduce the number of parameters to be estimated and to reduce possible collinearity issues, as past studies have done. ${ }^{5,9}$ Future studies should make an effort to collect larger samples as a way of measuring associations between each SDT construct independently, enjoyment, intention to continue exercising, and exercise persistence.

The "lack of persistence" does not necessarily mean that the participants have stopped exercising. It could mean that they have simply transferred their exercise elsewhere (eg, outdoor exercise, moved to a different gym). This limitation could be addressed in future research by asking non-persistent individuals to report if they were exercising at another gym or context.

The results of this study can encourage future researchers to test this hypothesized sequence on health-related outcomes (eg, healthy eating). Silva and Vieira ${ }^{59}$ in a sample with obese individuals revealed that a 1 -year SDT intervention is capable of increasing physical activity adherence. Similarly, other experimental studies ${ }^{6,60}$ have shown that supportive behaviors are associated with higher intentions toward exercising and self-reported exercise commitment.

\section{CONFLICT OF INTEREST}

The authors declare no conflict of interests.

\section{ETHICAL APPROVAL}

Approval from the Ethical Committee of Beira Interior University (CE-UBI-pJ-2018-044:ID683) was obtained.

\section{ORCID}

Filipe Rodrigues (iD https://orcid.org/0000-0003-1327-8872 Henrique Pereira Neiva (iD https://orcid. org/0000-0001-9283-312X

\section{REFERENCES}

1. EC. Special Eurobarometer 472 - Sport and Physical Activity.2018;1-133.

2. Ryan R, Deci E. Self-determination theory. Basic Psychological Needs in Motivation, Development, and Wellness. New York: Guildford Press; 2017.

3. Rodrigues F, Bento T, Cid L, et al. Can interpersonal behavior influence the persistence and adherence to physical exercise practice in adults? A systematic review. Front Psychol. 2018;9:2141.

4. Vallerand R, Toward A. Hierarchical model of intrinsic and extrinsic motivation. Adv Exper Soc Psychol. 1997;29:271-360.

5. Pulido J, Sanchez-Oliva D, Amado D, Gonzalez-Ponce I, SanchezMiguel P. Influence of motivational processes on enjoyment, boredom and intention to persist in young sportspersons. S Afr J Res Sport Ph. 2014;36:135-149.

6. Ntoumanis N, Thogersen-Ntoumani C, Quested E, Hancox J. The effects of training group exercise class instructors to adopt a motivationally adaptive communication style. Scand J Med Sci Sports. 2017;27:1026-1034.

7. Edmunds J, Ntoumanis N, Duda J. Testing a self-determination theory-based teaching style intervention in the exercise domain. Eur J Soc Psychol. 2008;38:375-388. 
8. Bartholomew K, Ntoumanis N, Ryan R, Thogersen-Ntoumani C. Psychological need thwarting in the sport context: assessing the darker side of athletic experience. J Sport Exerc Psychol. 2011;1:75-102.

9. Monteiro D, Pelletier L, Moutão J, Cid L. Examining the motivational determinants of enjoyment and the intention to continue of persistent competitive swimmers. Int J Sport Psychol. 2018;49(484):504

10. Gardner L, Magee C, Vella S. Social climate profiles in adolescent sports: Associations with enjoyment and intention to continue. $J$ Adolesc. 2016;52:112-123.

11. Ajzen I. The theory of planned behavior. Organ Behav Hum Decis Process. 1991;50:179-211.

12. Edmunds J, Ntoumanis N, Duda J. A test of self-determination theory in the exercise domain. J Appl Soc Psychol. 2006;36:2240-2265.

13. Edmunds J, Ntoumanis N, Duda J. Adherence and well-being in overweight and obese patients referred to an exercise on prescription scheme: A self-determination theory perspective. Psychol Sport Exerc. 2007;8:722-740.

14. Ng J, Ntoumanis N, Thogersen-Ntoumani C, Stott K, Hindle L. Predicting psychological needs and well-being of individuals engaging in weight management: the role of important others. Appl Psychol Health Well-Being. 2013;5:291-310.

15. Teixeira D, Silva M, Palmeira A. How does frustration make you feel? A motivational analysis in exercise context. Motiv Emot. 2018;42:419-428.

16. Puente R, Anshel M. Exercisers' perceptions of their fitness instructor's interacting style, perceived competence, and autonomy as a function of self-determined regulation to exercise, enjoyment, affect, and exercise frequency. Scand J Psychol. 2010;51:38-45.

17. Hagger M, Hardcastle S, Chater A, Mallett C, Pal S, Chatzisarantis $\mathrm{N}$. Autonomous and controlled motivational regulations for multiple health-related behaviors: between- and within-participants analyses. Health Psychol Behav Med. 2014;2:565-601.

18. Heiestad H, Rustaden A, Bo K, Haakstad L. Effect of regular resistance training on motivation, self-perceived health, and quality of life in previously inactive overweight women: a randomized, controlled trial. BioMed Res Int. 2016;2016:3815976

19. Hagger M. Habit and physical activity: Theoretical advances, practical implications, and agenda for future research. Psychol Sport Exerc. 2019;42:118-129.

20. Armitage C. Can the theory of planned behavior predict the maintenance of physical activity? Health Psychol. 2005;24:235-245.

21. Gardner L, Magee C, Vella S. Enjoyment and behavioral intention predict organized youth sport participation and dropout. J Phys Act Health. 2017;14:861-865.

22. Balish S, McLaren C, Rainham D, Blanchard C. Correlates of youth sport attrition: A review and future directions. Psychol Sport Exerc. 2014;15:429-439.

23. Crane J, Temple V. A systematic review of dropout from organized sport among children and youth. Eur Phys Educ Rev. 2014;21:114-131.

24. Rodrigues F, Pelletier L, Neiva H, Teixeira D, Cid L, Monteiro D. Initial validation of the Portuguese version of the Interpersonal Behavior Questionnaire (IBQ \& IBQ-Self) in the context of exercise: Measurement invariance and latent mean differences. Curr Psychol. 2019;1-12.

25. Rodrigues F, Hair J, Neiva H, Teixeira D, Cid L, Monteiro D. The basic psychological need satisfaction and frustration scale in exercise (BPNSFS-E): validity, reliability, and gender invariance in Portuguese exercisers. Percept Mot Skills. 2019;126(5):949-972.
26. Cid L, Monteiro D, Teixeira D, et al. The behavioral regulation in exercise questionnaire (BREQ-3) portuguese-version: evidence of reliability, validity and invariance across gender. Front Psychol. 2018;9:1940.

27. Pelletier L, Fortier M, Vallerand R, Brière N. Associations among perceived autonomy support, forms of self regulation, and persistence: a prospective study. Motiv Emot. 2001;25:279-306.

28. Jowett S, Adie J, Bartholomew K, Yang S, Gustafsson H, LopezJiménez A. Motivational processes in the coach-athlete relationship: A multi-cultural self-determination approach. Psychol Sport Exerc. 2017;32:143-152.

29. Teques P, Calmeiro L, Silva C, Borrego C. Validation and adaptation of the Physical Activity Enjoyment Scale (PACES) in fitness group exercisers. J Sport Health Sci. 2017.

30. Ajzen I. Constructing a TPB questionnaire: Conceptual and methodological considerations. University of Massachusetts; 2006.

31. Gucciardi D, Jackson B. Understanding sport continuation: an integration of the theories of planned behaviour and basic psychological needs. J Sci Med Sport. 2015;18:31-36.

32. Sarrazin P, Vallerand R, Guillet E, Pelletier L, Cury F. Motivation and dropout in female handballers: a 21-month prospective study. Eur J Soc Psychol. 2002;32:395-418.

33. Buckworth J, Dishman R. Exercise Psychology. Champaign: Human Kinetics; 2002.

34. Prochaska J, DiClemente C. Transtheoretical therapy: Toward a more integrative model of change. Psychother Theory Res Pract. 1982;19:276-288.

35. Allison P. Multiple imputation for missing data: a cautionary tale. Sociol Methods Res. 2000;28:301-309.

36. Byrne B. Structural equation modeling with AMOS. Basic concepts, applications, and programming, 3rd: edn. New York: Taylor \& Francis Group, LLC; 2016

37. Kline R. Principles and practice of structural equation modelling, 3rd edn. New York: The Guildford Press; 2016.

38. Hair J, Black W, Babin B, Anderson R. Multivariate data analysis, 7th edn. New Jersey: Pearson Educational Inc; 2014:816.

39. Marsh H, Hau K, Wen Z. In search of Golden Rules: comment on hypothesis-testing approaches to setting cutoff values for fit indexes and dangers in overgeneralizing Hu and Bentler's (1999) Findings. Struct Equ Modeling. 2004;11:320-341.

40. Worthington R, Whittaker T. Scale development research: a content analysis and recommendations for best practices. Counsel Psychol. 2016;34:806-838.

41. Faul F, Erdfelder E, Buchner A, Lang A-G. Statistical power analyses using $\mathrm{G}^{*}$ Power 3.1: tests for correlation and regression analyses. Behav Res Methods. 2009;41:1149-1160.

42. Monteiro D, Teixeira D, Travassos B, et al. Perceived effort in football athletes: the role of Achievement Goal Theory and SelfDetermination Theory. Front Psychol. 2018;9:1575.

43. Teques P, Calmeiro L, Martins H, Duarte D, Holt N. Mediating effects of parents' coping strategies on the relationship between parents' emotional intelligence and sideline verbal behaviors in youth soccer. J Sport Exerc Psychol. 2018;40:153-162.

44. Hayes A. Introduction to Mediation, Moderation, and Conditional Process Analysis, 2nd edn. New York: Guilford Press; 2018.

45. Shrout $\mathrm{P}$, Bolger N. Mediation in experimental and nonexperimental studies: New procedures and recommendations. Psychol Methods. 2002;7:422-445.

46. Cheung G, Rensvold R. Evaluating Goodness-of-Fit Indexes for testing measurement invariance. Struct Equ Modeling. 2002;9:233-255. 
47. Nevitt J, Hancock G. Performance of Bootstrapping approaches to model test statistics and parameter standard error estimation in Structural Equation Modeling. Struct Equ Modeling. 2001;8:353-377.

48. Teixeira P, Carraca E, Markland D, Silva M, Ryan R. Exercise, physical activity, and self-determination theory: a systematic review. Int J Behav Nutr Phys Act. 2012;9:78.

49. Assor A, Vansteenkiste M, Kaplan A. Identified versus introjected approach and introjected avoidance motivations in school and in sports: The limited benefits of self-worth strivings. J Educ Psychol. 2009;101:482-497.

50. Sheldon K, Osin E, Gordeeva T, Suchkov D, Sychev O. Evaluating the dimensionality of self-determination theory's relative autonomy continuum. Person Soc Psychol Bull. 2017;43:1215-1238.

51. Vlachopoulos S, Neikou E. A prospective study of the relationships of autonomy, competence, and relatedness with exercise attendance, adherence, and dropout. J Sports Med Phys Fitness. 2007;47:475-482.

52. Rocchi M, Pelletier L. How does coaches' reported interpersonal behavior align with athletes' perceptions? Consequences for female athletes' psychological needs in sport. Sport Exerc Perform Psychol. 2018;7:141-154.

53. Teixeira D, Marques M, Palmeira A. Associations between affect, basic psychological needs and motivation in physical activity contexts: Systematic review and meta-analysis. Revista Iberoamericana de Psicologia del Ejercicio y el Deporte. 2018;13:225-233.

54. Moreno-Murcia J, Huéscar Hernández E, Ruiz L. Perceptions of controlling teaching behaviors and the effects on the motivation and behavior of high school physical education students. Int $J$ Environ Res Public Health. 2018;15(10):2288.

55. Gunnell K, Crocker P, Wilson P, Mack D, Zumbo B. Psychological need satisfaction and thwarting: A test of Basic Psychological
Needs Theory in physical activity contexts. Psychol Sport Exerc. 2013;14:599-607.

56. Vansteenkiste M, Ryan RM. On psychological growth and vulnerability: Basic psychological need satisfaction and need frustration as a unifying principle. J Psychother Integr. 2013;23:263-280.

57. Hagger M, Chatzisarantis N, Biddle S. A meta-analytic review of the theories of reasoned action and planned behavior in physical activity: predictive validity and the contribution of additional variables. J Sport Exerc Psychol. 2002;24:3-32.

58. Sylvester B, Curran T, Standage M, Sabiston C, Beauchamp M. Predicting exercise motivation and exercise behavior: A moderated mediation model testing the interaction between perceived exercise variety and basic psychological needs satisfaction. Psychol Sport Exerc. 2018;36:50-56.

59. Silva M, Vieira P, Coutinho S, et al. Using self-determination theory to promote physical activity and weight control: a randomized controlled trial in women. J Behav Med. 2010;33:110-122.

60. Silva M, Markland D, Carraca E, et al. Exercise autonomous motivation predicts 3-yr weight loss in women. Med Sci Sports Exerc. 2011;43:728-737.

How to cite this article: Rodrigues F, Teixeira DS, Neiva HP, Cid L, Monteiro D. The bright and dark sides of motivation as predictors of enjoyment, intention, and exercise persistence. Scand J Med Sci Sports. 2019;00:1-14. https://doi.org/10.1111/ $\underline{\text { sms. } 13617}$ 